\title{
Uma (re)leitura do romance A Caverna, de José Saramago, à luz dos Surveillance Studies ${ }^{1}$
}

\section{João Rodrigues \\ Instituto Politécnico de Beja/Instituto de Literatura Comparada Margarida Losa}

Resumo: Partindo do suporte teórico fornecido pelos Surveillance Studies, o presente estudo visa dar um contributo para uma (re)leitura do romance A Caverna, de José Saramago, com base na análise da representação da vigilância. Deste modo, será dada especial atenção aos contextos de vigilância mais relevantes no romance, bem como à configuração do espaço em que, na narrativa, a vigilância se torna mais evidente- o Centro, um espaço de contornos alegóricos onde ganham forma múltiplos processos intrínsecos à sociedade contemporânea na era da globalização, como, por exemplo, o esbatimento das fronteiras entre o espaço público e o espaço privado e a reorganização da geografia urbana em função da prática do consumo, processos esses alicerçados, em grande medida, na disseminação de mecanismos de vigilância. Além disso, será igualmente analisada a construção das figuras vigilantes e vigiadas e, por fim, explorar-se-á o modo como, no texto, se privilegia a exposição e a questionação de subtis práticas de vigilância, num exercício de resistência, em que assenta uma parte significativa da dimensão crítica do romance.

Palavras-chave: A Caverna, vigilância, espaço urbano, Surveillance Studies

\begin{abstract}
Drawing on the theoretical input provided by the Surveillance Studies, this study aims to contribute to a re-reading of the novel The Cave [A Caverna] by José Saramago, based on the analysis of the representation of surveillance in the text. This article focuses on the most relevant surveillance contexts in the novel as well as on the spatial configuration of the "Centre", an allegorical space of key importance in the narrative in which surveillance plays a crucial role and where one can identify various features of our
\end{abstract}


globalised society, such as the fading border between public and private space and the reorganisation of the city in order to promote consumerism. This analysis not only explores the representation of the "watchers" and the "watched", but it also highlights the way in which subtle surveillance practices are disclosed and questioned in the context of the novel's critical perspetive of our contemporary capitalist society.

Keywords: The Cave, surveillance, urban space, Surveillance Studies

Desde a sua publicação no ano 2000, o romance A Caverna, de José Saramago, tem merecido a atenção de diversos académicos que, em múltiplas linhas de investigação, se têm debruçado sobre diferentes dimensões do romance. Destas podemos destacar a relação de intertextualidade estabelecida com o mito da Caverna de Platão e a representação crítica do consumismo doentio e da dinâmica feroz do capitalismo na era da globalização. É de notar, a este propósito, o facto de numerosos estudos se perfilarem numa lógica eminentemente interdisciplinar, em que o olhar saramaguiano sobre a contemporaneidade é lido a partir de perspetivas teóricas de várias disciplinas, tais como os estudos culturais, os estudos sociológicos ou até mesmo os estudos de marketing.

Foi precisamente nesse âmbito do cruzamento de olhares de diferentes disciplinas académicas que se me afigurou como pertinente percorrer o romance à luz dos Surveillance Studies, uma recente área de estudos que promove a discussão em torno da temática da vigilância, temática essa que considero passível de exploração mais pormenorizada neste texto saramaguiano, nele constituindo objeto de problematização incontornável.

De modo necessariamente sucinto, importa, neste contexto, destacar que, especialmente desde os finais do século XX, os Surveillance Studies se têm consolidado como um campo de estudos multidisciplinar que, recolhendo contributos de áreas tão diversas como a sociologia, a filosofia ou a geografia urbana, entre muitas outras, visa promover uma reflexão sólida sobre os processos de vigilância intrínsecos à sociedade contemporânea, em 
que o quotidiano é crescentemente escrutinado (Lyon 2007: 19ss.; Marx 2012: xxvii). Pensemos em como os mais simples gestos da nossa rotina se encontram hoje sujeitos a formas de registo, processamento e análise sempre que, por exemplo, navegamos na Internet, fazemos um pagamento com cartão multibanco ou somos captados por sistemas de videovigilância. É das implicações sociais e políticas dessa proliferação de mecanismos de vigilância que se ocupam os Surveillance Studies, sem, contudo, procederem a uma redutora "demonização" da vigilância, mas, antes, a uma reflexão sobre todo um leque de gradações entre as suas duas facetas opostas. David Lyon, um dos nomes proeminentes deste campo de estudos, defende que a vigilância, tal como Jano, tem duas "caras": care e control, facetas essas que muitas vezes se intercetam (Lyon 2001: 3s.).

No âmbito desta discussão, vários autores têm refletido sobre contextos diversos como, por exemplo, a vigilância militar, as medidas securitárias de combate ao terrorismo, o policiamento, a administração estatal, as potencialidades da vigilância eletrónica, a supervisão no mundo laboral ou ainda o papel da vigilância na reconfiguração do espaço citadino e em esferas privilegiadas de consumo (cf., por ex., Lyon 2007; Ball et alii 2012). Julgo serem precisamente estes dois últimos domínios de reflexão os mais úteis para a leitura d'A Caverna.

Recordemos que a ação do romance gira em torno de Cipriano Algor, um homem viúvo de 64 anos, em cuja casa residem também a filha e o genro, Marta e Marçal. Oleiro de profissão, Cipriano dedica-se à produção de artefactos de barro que vende para um estabelecimento de grandes dimensões, localizado na cidade e simplesmente designado por o "Centro", aonde o protagonista se desloca regularmente não só para transportar os seus produtos mas também para, de dez em dias, ir buscar e levar o seu genro. Integrado nas equipas de segurança do Centro, o jovem Marçal aspira a uma promoção na carreira e à oportunidade de, com isso, vir a usufruir da possibilidade de residir num dos apartamentos aí disponíveis para os funcionários.

A rotina de Cipriano é, porém, abalada quando este recebe a notícia de que o Centro irá suspender a compra dos artigos de barro, que serão substituídos por outros, de plástico, mais baratos e rentáveis ao negócio. A subsistência de Cipriano é, pois, colocada em risco e 
torna-se cada vez mais real a necessidade de o protagonista ter de abandonar a própria casa para se acomodar, com Marta e Marçal, no exíguo espaço milimetricamente delimitado a que cada família tem direito no Centro. Antes disso, Cipriano lança-se num projeto de produção de figuras de barro, que vem a revelar-se um malogro a nível económico. A mudança para o Centro afigura-se, pois, como inevitável, ainda que não seja definitiva, como nos revela o final do romance.

Como tem sido amplamente apontado pela crítica, a estrutura do romance posiciona a personagem central entre dois espaços-chave: por um lado, o universo da sua casa e da olaria, no campo, e, por outro, o Centro, na cidade, espaços esses que se assumem, num jogo dicotómico, como icónicos de diferentes modelos de sociedade. Enquanto o espaço da olaria assenta na força do trabalho manual e no poder individual da criação do pequeno produtor tradicional, o Centro surge como espaço representativo de uma economia dominada pelos interesses das grandes superfícies comerciais, pelo princípio da estandardização e pela consequente anulação do indivíduo numa sociedade materialista marcada pelo consumismo desenfreado e subjugada aos ditames do capitalismo selvagem (cf., por ex., Rollanson 2004; Guimarães 2011). Leiam-se, a este propósito, as palavras de José Bañón, que alarga o alcance deste contraste entre espaços, referindo-se também à vigilância como um dos elementos-chave da dicotomia em causa: "A Caverna vai opor [...] as ideias de povoação e cidade. [...] Esta oposição precipita na noção de liberdade, de vida ao ar livre e de vida em clausura, de ar puro e de ar viciado, de vida sem espias e de vida vigiada no Centro." (Bañón 2004: 303; cf., igualmente, Arnaut 2008: 48).

Neste breve estudo, centrar-me-ei, pois, no espaço do Centro por ser nele que, no romance, a vigilância se destaca como um elemento preponderante. Para isso, e fazendo uso de manancial teórico fornecido pelos Surveillance Studies, procurarei deter-me na representação dos mecanismos de vigilância operacionalizados na configuração do Centro, bem como, por fim, aferir de que maneira, na narrativa, são equacionados espaços de resistência.

Na sua análise da vigilância no espaço urbano, David Lyon confere especial destaque aos surveillant playspaces, definidos como locais de consumo associados ao lazer, tais como 
os parques temáticos, os casinos e os centros comerciais:

Shopping malls have become classic surveillant playspaces because, for all their emphasis on entertainment and as community meeting centres, malls are intended to be places of continuous consumption. This is built into the architecture and the ground plan, which lead consumers from location to location or oblige them to pass certain products en route to others, but it is also the purpose of the ubiquitous surveillance systems in the mall. While the cameras may have the intention of checking for shoplifters or monitoring the ways that staff use the till, they are also intended to keep shopper traffic moving and to minimize the risks of non-consumers - especially young people hanging out or panhandlers soliciting for loose change - contaminating the purchasing environment. (Lyon 2007: 108)

Os centros comerciais afiguram-se, assim, como espaços em cuja estrutura a vigilância se encontra embutida com o objetivo de criar um ambiente totalmente condicionado de modo a garantir a segurança necessária à prática do consumo e a afastar quaisquer elementos perturbadores dessa mesma prática. 0 contributo de Lyon auxilia-nos, pois, na leitura do espaço do Centro no romance. Detenhamo-nos, para já, no momento em que o edifício é referido pela primeira vez no texto:

[...] [U]ma avenida em linha recta levava-os aos seus destinos, ali onde era esperado o guarda interno Marçal Gacho, além onde deixaria a sua carga o oleiro Cipriano Algor. Ao fundo, um muro altíssimo, escuro, muito mais alto que o mais alto dos prédios que ladeavam a avenida, cortava abruptamente o caminho. Na realidade, não o cortava, supô-lo era o efeito de uma ilusão de óptica, havia ruas que, para um lado e para outro, prosseguiam ao longo do muro, o qual, por sua vez, muro não era, mas sim a parede de uma construção enorme, um edifício gigantesco, quadrangular, sem janelas na fachada lisa, igual em toda a sua extensão. Cá estamos, disse Cipriano Algor [...]. (Saramago 2000: 17 , negritos meus)

A este propósito, é de salientar não só o facto de o Centro ser apresentado, pela sua localização estratégica e dimensão megalómana, como uma espécie de “Acrópole”, mas também que, não por acaso, o Centro é associado, à partida, a um efeito de "ilusão de ótica", o que remete o leitor, de imediato, para a configuração artificial daquele espaço, onde serão 
constantes as discrepâncias entre a aparência e a realidade, especialmente no que aos mecanismos de sedução do consumidor diz respeito. Além disso, a cor escura e a aparência estandardizada, bem como o desenho retilíneo e a ausência de aberturas para o exterior em grande parte da fachada apontam para a estrutura de uma fortaleza ou prisão. Na verdade, são vários os passos textuais em que o Centro é criticamente percecionado como uma espécie de cárcere gigantesco, especialmente por Cipriano Algor, que vive permanentemente perturbado pela ideia da mudança:

E é ali, disse Cipriano Algor entredentes, que o meu querido genro quer que eu vá viver, por trás de uma daquelas janelas que não se podem abrir, dizem eles que é para não alterar a estabilidade térmica do ar condicionado, mas a verdade é outra, as pessoas podem suicidar-se se quiserem, mas não atirando-se de cem metros de altura para a rua, é um desespero que dá demasiado nas vistas e espevita a curiosidade mórbida dos transeuntes, que logo querem saber porquê. (idem: 101)

Esta leitura do espaço do Centro como uma prisão (cf., por ex., Bañón 2004: 304) não pode ser desligada dos mecanismos de vigilância que nele proliferam, aos quais o narrador concede acesso ao leitor por duas vias principais: ora através da perspetiva de Cipriano, que incarna a visão de um utente que se digladia criticamente com a configuração daquele espaço percecionado como opressor, ora a partir do olhar de Marçal, que representa, por seu turno, a voz de alguém que conhece o sistema por dentro. É, pois, do cruzamento destas duas perspetivas que se consubstancia, no texto, a representação da vigilância.

A este propósito, é de sublinhar a referência recorrente à presença de câmaras, as quais são entendidas de modo distinto pelo protagonista e pelo genro. Em jeito de exemplo, atentemos num trecho enquadrado na visita que antecede a mudança da família para o Centro, em que Marçal guia a mulher e o sogro naquele espaço:

A parte do ascensor virada para o interior era toda envidraçada. 0 ascensor ia atravessando vagarosamente os pavimentos, mostrando sucessivamente os andares, as galerias, as lojas, as escadarias de aparato, as escadas rolantes, os pontos de encontro [...]. E esta velocidade para que serve, perguntou Cipriano Algor, A esta velocidade os elevadores são usados apenas como meio complementar de vigilância, disse Marçal. Não chegam para isso os guardas, os detectores, as câmaras 
de vídeo e o resto da tralha bisbilhoteira, tornou a perguntar Cipriano Algor. Passam por aqui todos os dias muitas dezenas de milhares de pessoas, é necessário manter a segurança, respondeu Marçal, com o rosto tenso e um reproche de contrariedade na voz. (Saramago 2000: 277s.)

Deparamos, neste trecho, com o jogo dicotómico entre as duas facetas da vigilância apontadas por Lyon - care e control. Cipriano perceciona toda aquela parafernália de mecanismos de vigilância como invasora e como uma forma de controlo; por seu turno, Marçal, o guarda, e portanto uma das peças daquele sistema, defende-a, resignadamente, como um "mal" necessário em nome da segurança, segurança essa que constitui precisamente um dos elementos basilares na publicidade sedutora do Centro: "VIVA EM SEGURANÇA, VIVA NO CENTRO" (idem: 92). Além da longa enumeração de instrumentos de vigilância por Cipriano, que enfatiza a perceção daquele espaço como um lugar de contornos asfixiantes, ou mesmo como um "não-lugar" na aceção de Marc Augé (1992), é também de destacar a expressividade do motivo da transparência; a lenta velocidade dos elevadores panorâmicos concorre para a exposição de todos os utentes daquela "cidade artificial" a uma visão de caráter totalizante, a que é impossível escapar.

Neste contexto, torna-se pertinente, na minha opinião, a relação entre esta configuração espacial e um dos conceitos mais profícuos no âmbito dos Surveillance Studies - refiro-me ao conceito de panóptico, originalmente cunhado por Jeremy Bentham no século XVIII e recuperado por Michel Foucault em 1975 na sua obra Surveiller et Punir. Naissance de la Prison, em que o filósofo francês sintetiza o funcionamento das sociedades disciplinares. Recordemos que o conceito de panóptico, inicialmente aplicado ao espaço de uma prisão e posteriormente estendido a vários espaços análogos, consiste numa estrutura em que um vigilante, isolado numa torre central, detém uma visão panorâmica sobre todos os prisioneiros. 0 vigilante, na escuridão, remete-se à invisibilidade, ao passo que os vigiados, permanentemente iluminados, se resignam a uma visibilidade constante. Perante a incerteza de estarem a ser observados, mas conscientes dessa possibilidade, moldam constantemente o seu próprio comportamento, tornando-se, nas palavras de Foucault, em “corpos dóceis" (Foucault 1975). 
Também no romance A Caverna, podemos encontrar marcas desta dinâmica própria do panóptico. A propósito de uma das deambulações de Cipriano pelo Centro em busca das misteriosas escavações subterrâneas que servirão de pretexto para a evidente recriação da Alegoria da Caverna de Platão no final do romance, podemos ler: "A quem teve de dar prontas e completas explicações foi a um guarda que, atraído pelo ruído ou, mais provavelmente, guiado pelas imagens do circuito interno de vídeo, lhe foi perguntar quem era e o que fazia naquele local." (Saramago 2000: 310).

Penso que, não por acaso, no romance, a sala central dos circuitos de videovigilância não é revelada precisamente como uma estratégia narrativa de, no texto, recriar essa invisibilidade do centro nevrálgico do poder. 0 efeito da presença dos mecanismos de videovigilância manifesta-se, sobretudo, nas reações desencadeadas nos seguranças, outro dos mecanismos de vigilância de importância nuclear na configuração dos surveillant playspaces. Trata-se de figuras robóticas, e por isso anónimas (à exceção de Marçal), representadas como uma espécie de exército destinado a garantir a manutenção da ordem. O perfil militarizado destes indivíduos, frequentemente apontado nos estudos sobre a vigilância (por ex., Lyon 2007, 36s.), torna-se evidente, no romance, num dos diálogos entre Cipriano e Marçal: "O facto de eu ser guarda não fez de mim um polícia ou militar, respondeu Marçal secamente, Não fez mas ficas lá perto, na fronteira" (idem: 106). Concretiza-se, assim, neste e em outros passos do texto, a crítica ao excessivo poder conferido a estas figuras, caracterizadas não só pelas fardas que envergam mas também pelo modo mecânico como agem, como peças de uma complexa engrenagem de monitorização. Naquele espaço, todas as movimentações, mesmo que inócuas, que fujam à rotina e ao exercício do consumismo parecem ser, de facto, objeto de análise imediata, como exemplificam os seguintes excertos:

Sentou-se finalmente na furgoneta, olhou o relógio, ainda teria de esperar quase uma hora para ir recolher o genro, veio-lhe à cabeça a ideia de entrar no Centro, há muito tempo que não usa as portas do público, seja para olhar, seja para comprar, as compras sempre as fez Marçal [...], e entrar só para olhar não é, passe a redundância, bem-visto, alguém que ande lá dentro de mãos a abanar pode 
estar certo que não tardará a ser objecto de especial atenção por parte dos guardas [...] (idem: 99, negritos meus).

Copiei estas frases de alguns cartazes expostos, disse [Cipriano], espero não ter chamado a atenção de nenhum espia ou observador, Também o espero, disse Marçal de mau humor, É suspeito copiar frases que estão expostas para os clientes lerem, perguntou Cipriano Algor, Lê-las é normal, copiá-las não, e tudo o que não seja normal é, pelo menos, suspeito de anormalidade. (idem: 312, negritos meus)

O simples deambular, sem comprar, ou quaisquer outras atividades que se desviem da prática do consumo são, pois, encaradas como uma potencial ameaça, o que nos remete para uma nova função deste panóptico: o seu objetivo deixa de ser apenas observar para passar a consistir também na exclusão de todos os elementos perturbadores, ou "contaminadores", como diria Lyon (2007: 108), daquela ordem estandardizada. Legitimase, assim, a classificação daquela estrutura como um ban-opticon, um conceito cunhado por Didier Bigo (2006) para designar o complexo aparato de vigilância que procura manter afastados grupos específicos como os imigrantes ilegais e os suspeitos de terrorismo, e trazido, de forma produtiva, para os Surveillance Studies por David Lyon e Zygmunt Bauman. Como afirma Lyon, “[t]he opticon has a new purpose, to 'ban' some, to exclude” (Lyon 2007: 65). Em consonância com Lyon, Bauman afirma no volume Liquid Surveillance:

I suggest that CCTV cameras surrounding gated communities and dotting shopping malls [...] are the principal - the most common and pattern-setting - specimens of ban-optical devices [...]. Another task of ban-optical appliances [...] is to promptly spot individuals who show signs of unwillingness to fall into line or who plot to breach those binding patterns. (Bauman/Lyon 2013: 63s.)

Na verdade, na própria publicidade sedutora do Centro, frequentemente referida ao longo do texto, encontra-se implícita esta função do espaço: num dos muitos cartazes que capta a atenção de Cipriano, pode ler-se: “[...] traga os seus amigos desde que comprem” (Saramago 2000: 312, negrito meu).

Podemos, pois, afirmar que, n’A Caverna, a vigilância é representada como um instrumento de consolidação do modelo de sociedade representado pelo Centro, modelo 
esse que se traduz, em parte, numa profunda reconfiguração do espaço urbano. No romance, o Centro é apresentado como um espaço onde os trabalhos de expansão decorrem incessantemente, dia e noite, chegando, aliás, a ser caracterizado por Marçal como "uma cidade dentro de outra cidade" (idem: 258) ou por Cipriano como "maior do que a própria cidade, sendo uma parte é maior que o todo" (idem: 259). Esta hipérbole, de contornos paradoxais, implícita na observação de Cipriano, reforça o efeito de desorientação provocado pela célere e radical transformação em curso na cidade, onde a lógica de organização daquele espaço passará a ser a regra noutras zonas entretanto "engolidas" por aquela estrutura megalómana. No dizer de José Bañón,

[o] Centro, parece aventurar o escritor, é a cidade que nos espera: uma cidade ensimesmada e autosuficiente, gigante e densa, amuralhada e furada, infinita e labiríntica; [...] uma cidade condicionada e vigiada, artificial e mecânica, carcereira e inabitável, asséptica e inumana; uma cidade governada pelos princípios do mercado, da rentabilidade, da eficácia sem erros. (Bañón 2004: 309)

Para esta leitura concorre igualmente o parecer de Walter Siebel (2007), que se reporta ao facto de características atribuídas aos surveillant playspaces se aplicarem, cada vez mais, a outros espaços urbanos; por exemplo, zonas pedonais e turísticas passam a configurar-se como centros comerciais ao ar livre, onde proliferam mecanismos de vigilância que promovem a criação de uma espécie de redoma, num processo de fortificação da cidade, que, segundo Hille Koskela, resulta numa espécie de "prisão invertida": aqueles que não conseguem acompanhar a dinâmica do consumismo ou que a podem perturbar são deixados do lado de fora (Koskela 2000: 246). Assiste-se, pois, a um processo de homogeneização do espaço urbano, outrora, um espaço heterogéneo por excelência (Bauman 2011: 21ss., Kammerer 2008: 96ss.). A utilização do espaço público parece, pois, implicar a aceitação cega de normas, não havendo lugar para a sua discussão.

Também no romance, tal evolução é criticamente apontada não só nos diálogos entre Cipriano e Marçal, mas também na interação do protagonista com outros guardas do Centro, por exemplo, aquando da sua "investigação" de uma "porta secreta" que lhe desperta a curiosidade: 
O guarda pediu-lhe o cartão oficial de identidade, o cartão que o acreditava como residente, comparou a cara ao retrato incorporado em cada um, examinou à lupa as impressões digitais apostas nos documentos e, para terminar, recolheu uma impressão do mesmo dedo, que Cipriano Algor [...] premiu contra o que seria um leitor do computador portátil que o guarda extraíra de uma bolsa [...], ao mesmo tempo que ia dizendo, Não se preocupe, são formalidades, em todo o caso, aceite-me um conselho, não torne a aparecer por aqui, poderia arranjar complicações para a sua vida, [...] não há nada de secreto por trás desta porta [...], Se é como diz, por que é que não retiram a chapa, perguntou Cipriano Algor, Serve de chamariz para ficarmos a saber quem são as pessoas curiosas que moram no Centro. 0 guarda esperou que Cipriano Algor se afastasse [...], depois seguiu até que encontrou um colega, a quem [...] passou a missão [...], Se notares algo de suspeito, informa-me, para anexar ao relatório, assinaremos os dois. (Saramago 2000: 310s.)

Este panóptico, cujo poder é aqui reforçado pela sua configuração digital, adquire, assim, contornos distópicos, ou talvez mesmo orwellianos, no modo como procura anular, através da vigilância, qualquer tipo de questionação ou de resistência à ordem instituída.

$\mathrm{Na}$ verdade, a resistência à vigilância constitui um dos focos de interesse de muitos autores no âmbito dos Surveillance Studies. Num mundo em que a vigilância constitui um elemento incontornável, quaisquer formas de não conivência, sejam elas em protestos organizados, conforme explorado por autores como Torin Monahan (2006), ou individuais e espontâneas, como teorizado por Gary Marx (2003), adquirem uma dimensão política no modo como desafiam e interrompem, ainda que momentaneamente, a ordem instituída, através de práticas de contravigilância.

Como John Gilliom e Torin Monahan afirmam, na sua reflexão sobre a resistência quotidiana, torna-se útil recorrer, neste contexto, ao contributo de Michel de Certeau (Gilliom/Monahan 2012: 407). De facto, em vez de colocar em foco a perda de liberdade do indivíduo perante a imponência de mecanismos de poder, e em claro contraponto com a obra de Foucault Surveiller et Punir. Naissance de la Prison, Michel de Certeau destaca, em L'invention du quotidien. Arts de faire, a maneira como os indivíduos, através de táticas diversas, procuram tirar partido de lacunas do sistema de poder com que se confrontam nos espaços por onde se movimentam, criando uma espécie de "rede antidisciplina" 
(Certeau 1980; Prata 2012, 53s.). Dessa maneira, perde-se o enfoque na visão dos indivíduos como “corpos dóceis", de caráter eminentemente passivo, para se passar a privilegiar o seu desempenho como atores no processo de contestação da vigilância.

No romance $A$ Caverna, é também sobretudo no percurso da figura de Cipriano Algor que encontramos esse espaço de resistência quotidiana, não só na frequente questionação dos procedimentos cegos seguidos naquele espaço, mas também naquilo que parece ser a demanda de um "ângulo morto" naquele universo plenamente vigiado. Atentemos no início da descida de Cipriano às interditas escavações do Centro, onde o protagonista virá a deparar com os corpos de seis enigmáticas figuras que, tal como na Alegoria da Caverna de Platão, se encontram imobilizadas num banco de pedra diante de uma parede:

Tinha reparado que os monta-cargas [...] não estavam providos de câmaras de vídeo, pelo menos que se desse por elas, e se alguma houvesse, daquelas minúsculas e disfarçadas, o mais certo era que a atenção dos vigilantes da central se encontrasse fixada nos acessos exteriores e nos andares comerciais e de atracções. Se estivesse equivocado, não tardaria a sabê-lo. (Saramago 2000: 329, negritos meus)

Não por acaso, a propósito do seu regresso ao apartamento após aquela expedição, podemos também ler: "Eram quatro e meia. 0 monta-cargas levou-o ao trigésimo quarto andar. Ninguém o tinha visto" (idem: 334, negrito meu). Através da reprodução dos pensamentos de Cipriano, o leitor é confrontado com a perspetiva do vigiado, que, de modo a atingir o seu objetivo, procura assumir o papel de vigilante. Num plano inferior, e ao selecionar cuidadosamente o seu percurso, pensando nas implicações dos seus passos, a personagem assume uma postura desafiadora ao concretizar uma apropriação individual do sistema que percorre, evitando, do modo que lhe é possível, a visão das estruturas de vigilância presentes. Lembrando a analogia de Certeau a propósito das práticas microbianas do quotidiano, a visão terrena da personagem - tal como a de Dédalo - procura vencer a visão dos vigilantes - a de Ícaro -, que, apesar panorâmica, não consegue interpretar a totalidade que capta (Certeau 1980: 172).

Em suma, é através da simbólica fuga ao olhar totalizante daquele panóptico, num 
trajeto individual não captado pelo olhar do vigilante, que o protagonista consegue concretizar a sua resistência, fazer a descida às escavações subterrâneas e, assim, ver e assimilar a "verdade das coisas" (idem: 334) - que, de facto, aquele espaço, de que decidirá sair, ou a sociedade que ele representa, se resume a um cárcere, onde os prisioneiros nada mais veem do que sombras da realidade, tal como na Caverna de Platão. A resistência iniciada através do exercício de deambulação clandestina pelo vigiado labirinto do Centro, e concretizada na poderosa descoberta de contornos epifânicos que dela advém, constitui, numa nota de otimismo que marca o final do romance, o mote para a fuga sem destino definido por parte do protagonista e da sua família (Marta, Marçal, Isaura, com quem Cipriano deseja iniciar uma nova vida, e ainda o cão Achado), fuga essa que pode ser entendida como uma forma de libertação da opressão do Centro e da ordem por ele configurada (Arnaut 2008: 48).

No entanto, não de somenos importância é o facto de essa mesma ordem se reforçar permanentemente, tal como é estrategicamente sugerido pelas últimas linhas do texto, em que o leitor é confrontado, nas palavras de Marçal, com o conteúdo do mais recente cartaz do Centro: "BREVEMENTE, ABERTURA AO PÚBLICO DA CAVERNA DE PLATÃO, ATRACÇÃO EXCLUSIVA, ÚNICA NO MUNDO, COMPRE JÁ A SUA ENTRADA.” (Saramago 2000: 350). A ordem representada pelo Centro parece, no final do romance, já se ter apropriado, quase instantaneamente, daquela descoberta inicialmente entendida uma potencial ameaça, integrando-a na sua dinâmica de consumo (cf., p. ex., Londoño 2006, 176). Provavelmente, também naquele espaço, onde Cipriano conseguiu vislumbrar a "verdade", existam já câmaras de vigilância, instaladas no âmbito da contínua e implacável expansão do Centro, ou melhor, daquela Caverna, onde todos nós, volvidas quase duas décadas desde a publicação do romance, continuamos encarcerados e cada vez mais vigiados. 


\section{NOTA}

10 presente artigo resulta de uma comunicação apresentada no âmbito do Congresso Internacional José Saramago: 20 Anos com o Prémio Nobel, realizado em Coimbra, de 8 a 10 de outubro de 2018. Este artigo foi desenvolvido no âmbito do do Programa Estratégico “UID/ELT/00500/2019”, que é financiado por Fundos Nacionais através da FCT - Fundação para a Ciência e a Tecnologia.

\section{Bibliografia}

Arnaut, Ana Paula (2008), José Saramago, Lisboa, Edições 70.

Augé, Marc (1992), Non-Lieux. Introduction à une anthropologie de la surmodernité, Paris, Seuil.

Ball, Kirstie/Kevin Haggerty/David Lyon (eds.) (2012), Routledge Handbook of Surveillance Studies, London/New York, Routledge.

Bañón, José Joaquín Parra (2004), Pensamento Arquitectónico na Obra de José Saramago Acerca da Arquitectura da Casa, tradução de Margarita Correia, Lisboa, Caminho.

Bauman, Zygmunt (2011), Globalization. The Human Consequences, Cambridge/Malden, Polity Press [1998].

-- e David Lyon (2013), Liquid Surveillance, Cambridge/Malden, Polity Press.

Bigo, Didier (2006), "Security, exception, ban and surveillance", in David Lyon (ed.), Theorizing Surveillance: the Panopticon and beyond, Cullompton, Willan, 46-68.

de Certeau, Michel (1980), L'invention du quotidien. Arts de faire, Paris, Union Générale 
d'Editions.

Foucault, Michel (1975), Surveiller et punir. Naissance de la prison, Paris, Gallimard.

Gilliom, John/Torin Monahan (2012), "Everyday resistance", in Kirstie Ball/Kevin D. Haggerty/David Lyon (eds.), Routledge Handbook of Surveillance Studies, London/New York, Routledge, 405-411.

Guimarães, Andresa Fabiana B. (2011), O Trabalho e o Trabalhador aos Olhos de José Saramago. Análise de Alguns Procedimentos Literários nos Romances Levantado do Chão e A Caverna, Tese de Doutoramento apresentada à Faculdade de Filosofia, Letras e Ciências Humanas da Universidade de São Paulo, <http://www.teses.usp.br/teses/ disponiveis/8/8151/tde-04052012-100302/pt-br.php> (último acesso em 10/01/2019).

Kammerer, Dietmar (2008), Bilder der Überwachung, Frankfurt am Main, Suhrkamp.

Koskela, Hille (2000). “'The gaze without eyes': video-surveillance and the changing nature of urban space”, Progress in Human Geography, vol. 24, n. 2, 243-265.

Londoño, Manuel (2006), “Son iguales a nosotros'. Comentarios a La Caverna de José Saramago", Cuadernos de Filosofia Latinoamericana, vol. 27, n.o 94, 165-176.

Lyon, David (2001), Surveillance Society: Monitoring Everyday Life, Buckingham/Philadelphia: Open University Press.

-- (2007), Surveillance Studies: an Overview, Cambridge/Malden, Polity Press.

Marx, Gary (2003), “A Tack in the Shoe: Neutralizing and Resisting the New Surveillance”, Journal of Social Issues, vol. 59, n.ㅇ 2, 369-390.

-- (2012), “Your papers please': personal and professional encounters with surveillance”, in Kirstie Ball/Kevin Haggerty/David Lyon (eds.), Routledge Handbook of Surveillance Studies, London/New York, Routledge, xx-xxxi.

Monahan, Torin (2006), “Counter-surveillance as Political Intervention?”, Social Semiotics, 
vol. 16, n.. 4, 515-534.

Prata, Ana Filipa (2012), "Michel de Certeau, A Invenção do Quotidiano", in Susana Araújo/Ana Raquel Fernandes/Sandra Bettencourt (eds.), (In)Seguranças no Espaço Urbano. Perspetivas Culturais, V. N. Famalicão, Húmus, 53-54.

Rollanson, Christopher (2004), "Globalisation and Particularism in the Work of José Saramago: the Symbolism of the Shopping-Mall in A Caverna", Belén Martín-Lucas/Ana Bringas López (eds.), Global Neo-Imperialism and National Resistance: Approaches from Postcolonial Studies, Vigo, Servicio de Publicacións da Universidade de Vigo, 207-216.

Saramago, José (2000), A Caverna, 3.ㄹ edição, Lisboa, Caminho.

Siebel, Walter (2007), "Vom Wandel des öffentlichen Raumes", in Jan Wehrheim (ed.), Shopping Malls. Interdisziplinäre Betrachtungen eines neuen Raumtyps, Heidelberg, VS Verlag für Sozialwissenschaften, 77-94.

João Rodrigues licenciou-se, em 2003, em Línguas e Literaturas Modernas (variante de Estudos Ingleses e Alemães), na Faculdade de Letras da Universidade de Coimbra. Na mesma instituição frequentou, entre 2004 e 2007, o Mestrado em Estudos Germanísticos. Em 2015, concluiu o Doutoramento em Estudos Literários, Culturais e Interartísticos, na Faculdade de Letras da Universidade do Porto, com a apresentação de uma tese sobre a representação da vigilância em romances contemporâneos de expressão inglesa e alemã. Em 2018, após a realização da componente de Estudos Portugueses, concluiu a Licenciatura em Línguas, Literaturas e Culturas (variante de Estudos Portugueses e Alemães) na Faculdade de Ciências Sociais e Humanas da Universidade Nova de Lisboa. É colaborador do Instituto de Literatura Comparada Margarida Losa. Desde 2005, tem lecionado diversas unidades curriculares de Inglês e Alemão para fins específicos no ensino superior politécnico. 